\title{
Mitochondrial localization of non-histone protein HMGB1 during human endothelial cell-Toxoplasma gondii infection
}

\author{
Ana Carolina Stumbo a, Erika Cortez ${ }^{\text {a }}$, Carlos Alberto Rodrigues ${ }^{\text {b }}$, \\ Maria das Graças M.O. Henriques ${ }^{\mathrm{b}}$, Luís Cristóvão Porto ${ }^{\mathrm{a}}$, \\ Helene S. Barbosa ${ }^{\mathrm{c}}$, Laís Carvalho ${ }^{\mathrm{a}, *}$ \\ ${ }^{a}$ Laboratório Cultura de Células, Departamento de Histologia e Embriologia, Instituto de Biologia, Universidade do Estado do Rio de Janeiro, \\ UERJ, Av. Prof. Manoel de Abreu 444, $3^{\circ}$ andar, 20550-170 Rio de Janeiro, RJ, Brazil \\ ${ }^{\mathrm{b}}$ Laboratório de Farmacologia Aplicada, Fiocruz, RJ, Brazil \\ ${ }^{\mathrm{c}}$ Laboratório de Biologia Estrutural, IOC, Fiocruz, RJ, Brazil
}

Received 20 July 2007; revised 22 August 2007; accepted 29 August 2007

\begin{abstract}
Toxoplasma gondii is an obligate intracellular pathogen, replicating only within a specialized membrane-bounded cytoplasmic vacuole, the parasitophorous vacuole (PV), which interacts with host cell mitochondria. High mobility group box 1 (HMGB1), a known nuclear transcription factor, also may be involved in pathological conditions, whose function is to signal tissue damage. Using confocal microscopy, we have investigated the localization of HMGB1 and the mitochondria performance during interaction between human umbilical vein endothelial cells (HUVEC) and Toxoplasma. Immunofluorescence showed HMGB1 localization in HUVEC tubular mitochondria stained with Mito Tracker (MT). At $2 \mathrm{~h}$ post-infection, MT labeled spherical structures scattered throughout the cytoplasm and HMGB1 were still present. After $24 \mathrm{~h}$ of infection, long and tubular structures were localized around PVs and were double labeled by MT and HMGB1, suggesting a structural reorganization of the mitochondria over a long period of infection. For the first time, these results show there is HMGB1 in HUVEC mitochondria and that this protein could be playing a part in mitochondrial DNA events which are important for fission and fusion processes reported here during HUVEC-T. gondii infection.
\end{abstract}

(C) 2007 International Federation for Cell Biology. Published by Elsevier Ltd. All rights reserved.

Keywords: Human endothelial cell; Mitochondria; HMGB1; Toxoplasma gondii

\section{Introduction}

Mitochondria are dynamic organelles which appear as long tubular networks or single spherical organelles dependent of the equilibrium between fusion and fission processes (Bereiter-Hahn and Voth, 1994; Chan, 2006). These opposing processes are coordinated by 5 nuclear-encoded essential proteins (Bossy-Wetzel et al., 2003) and the physiological significance of the continual fusion and division of mitochondria is

\footnotetext{
* Corresponding author. Tel.: +55 2125876125 .

E-mail address: 1dc29@globo.com (L. Carvalho).
}

still unclear. A possible function for fusion could be a rescue mechanism for damaged mitochondria by exchange of mitochondrial DNA (mtDNA) and/or mitochondrial proteins (Jendrach et al., 2005). It has been demonstrated that mitochondrial fission appears important for progression of the apoptotic pathway (Chen and Chan, 2005; Parone and Martinou, 2006). Mitochondria may yet have a central role in integrating signals from pathogenic challenge and orchestrating an immune or apoptotic response, depending on the challenge (Seth et al., 2005). The role of mitochondria in apoptosis distinctly shows how mitochondria govern the homeostasis and wellbeing of an organism by regulating cell death in response to stress signals (Wang, 2001). 
The protozoan parasite, Toxoplasma gondii, infects humans and other mammals, causing clinical disease in immunocompromised individuals (Vidal et al., 2005). During congenital toxoplasmosis, infection of the endothelial cells lining the umbilical cord blood vessels is probably the main transmission route to the fetus (Woodman et al., 1991). T. gondii is an obligate intracellular pathogen, replicating within a specialized membrane-bounded cytoplasmic vacuole designated as parasitophorous vacuole (PV) formed in the cytoplasm of nearly all cell types (Carruthers and Boothroyd, 2007; Morisaki et al., 1995; Stumbo et al., 2002).

The PV maintenance is a critical step in parasite development. Once inside the host cell, the parasite avoids host cell defenses in order to meet its requirements for feeding and reproduction (Carruthers, 2002; Martin et al., 2007). The PV membrane (PVM) incorporates components from both the host cell and the parasite, thus establishing a hybrid membrane (Carvalho and de Souza, 1989; Pacheco-Soares and De Souza, 1998; Stumbo et al., 2002). T. gondii PVM exhibits a high affinity interaction with host cell endoplasmic reticulum and mitochondria in a process termed PVM-organelle association (de Melo et al., 1992; Sinai et al., 1997), once the $\mathrm{NH}_{2}$-terminal domain of ROP2, a parasite protein localized in PVM, is also suggested as having characteristics of a mitochondrial target signal (Sinai and Joiner, 2001).

High mobility group (HMG) of non-histone proteins can be divided into 3 readily identifiable families (HMGA, HMGB and HMGN) inducing specific changes in DNA and chromatin substrates. They also differentially affect a particular set of cellular processes, including transcription, replication, chromosomal changes during cell cycle, DNA repair and apoptosis (Bustin, 1999; Reeves and Adair, 2005). A coordinated activity of mitochondrial and nuclear process during different cellular events based on the mitochondrial localization of the HMGA1 protein, a known nuclear transcription factor, was recently proposed (Dement et al., 2005). Moreover, the nuclear protein HMGB1 is involved in pathological conditions including cancer and retroviral integration, as well as cytokine functioning to signal tissue damage (Muller et al., 2001). The nucleus of endothelial cell contains HMGB1 and studies have suggested that the endothelium may be a potential source of HMGB1 secretion in response to systemic infection (Mullins et al., 2004).

The localization of HMGB1 and the performance of mitochondria during interaction of human umbilical vein endothelial cell (HUVEC) with Toxoplasma gondii tachyzoites was the aim of our investigation.

\section{Materials and methods}

Human umbilical vein endothelial cell (HUVEC) cultures were obtained from umbilical cord by digestion with $0.06 \%$ collagenase Type IA (Sigma Chemical Co., St. Louis, MO, USA) according to a method modified from Jaffe et al. (1973). The cells were resuspended in Dulbecco's modified Eagle's medium (DMEM) containing 20\% heat-inactivated FCS, $50 \mu \mathrm{g} / \mathrm{ml}$ gentamicin and $2.5 \mu \mathrm{g} / \mathrm{ml}$ amphotericin and plated in 24-well plates with round coverslips pre-coated with $0.1 \%$ porcine gelatin. The cultures were kept for $48 \mathrm{~h}$ at $37{ }^{\circ} \mathrm{C}$ in $5 \% \mathrm{CO}_{2}$ in air.
Tachyzoites from the virulent RH strain of Toxoplasma gondii were maintained by intraperitoneal passages in female Swiss mice and were collected $72 \mathrm{~h}$ after infection (Carvalho and de Souza, 1989). The parasites were allowed to invade HUVEC for $30 \mathrm{~min}$ at $37^{\circ} \mathrm{C}$, at a multiplicity of infection of 5:1. Afterwards, the cultures were washed 3 times with medium to remove free parasites. The cells were then incubated for 2 and $24 \mathrm{~h}$ at $37^{\circ} \mathrm{C}$ in a humidified atmosphere containing $5 \% \mathrm{CO}_{2}$.

To identify the mitochondria, live cell cultures were labeled with MitoTracker Green FM (Molecular Probes, Eugene, OR, USA), a probe which accumulates in active mitochondria and then reacts with accessible thiol groups of proteins and peptides to form fluorescent aldehydic-fixable conjugates $(\lambda$ Ex. $490 \mathrm{~nm}, \lambda$ Em. $516 \mathrm{~nm}$ ). The endothelial cells (control or infected) were incubated with MitoTracker Green FM (1:250) for 15 min in serum-free medium, at $37^{\circ} \mathrm{C}$. After mitochondrial labeling, the cells were fixed with $4 \%$ paraformaldehyde, permeabilized with $0.5 \%$ Triton X-100 and immunolabeled with goat anti-human HMGB1 (Santa Cruz Biotechnologic, Inc., CA, USA) polyclonal primary antibody. The cells were washed and incubated with biotinylated anti-goat secondary antibody and Cy3-streptavidin (Zimed Laboratories, Inc., South San Francisco, CA, USA). The samples were washed, mounted and analyzed using a confocal laser scanning microscope (CLSM Fluoview 3.3, BX51Olympus).

\section{Results and discussion}

MitoTracker labeled human endothelial cells presented staining long tubular structures with typical mitochondria profile (Fig. 1A). Indirect immunofluorescence with anti-HMGB1 (Fig. 1B) combined with prior MitoTracker staining of HUVEC cultures revealed co-localization of HMGB1 protein with mitochondria (Fig. 1C). For the first time, it can be shown that HMGB1 is located inside the HUVEC mitochondria. Moreover, mitochondria displayed a tubular network radiating from perinuclear region toward the cell periphery, in a characteristic distribution already described for HUVEC (Jendrach et al., 2005) and other cell types (de Melo et al., 1992; Dement et al., 2005). There was a much more intense pattern of mitochondrial immunofluorescent staining for HMGB1, while nuclear immunolocalization was displayed only as very small dots scattered inside the whole nuclear area (Fig. 1B). This result is similar to previous findings suggesting the peak of mitochondrial localization for HMGA1, a molecule from HMG family, occurs in stage S/G2 of NIH3T3 cell cycle (Dement et al., 2005).

After $2 \mathrm{~h}$ of $T$. gondii infection, MitoTracker labeled spherical structures were scattered throughout the cytoplasm (Fig. 1D), characterizing a mitochondrial fragmentation in endothelial cells after parasite penetration. Despite mitochondria fragmentation, we also observed that HMGB1 protein was still co-localized into these spherical structures (Fig. 1E,F). After $24 \mathrm{~h}$ of infection, long tubular structures double-labeled for MitoTracker and anti-HMGB1 were localized around the parasitophorous vacuole and nucleus (Fig. 1G-I), suggesting a mitochondrial reorganization after long time infection.

Previous studies with VERO cells show the general form of host cell mitochondria, as well as their spatial distribution, changes during evolution of $T$. gondii intracellular parasitism (de Melo et al., 1992). Since mitochondria participate in a variety of cellular events, including the apoptotic control of infected cells (Seth et al., 2005), mitochondria fragmentation and posterior reorganization process observed in this work 

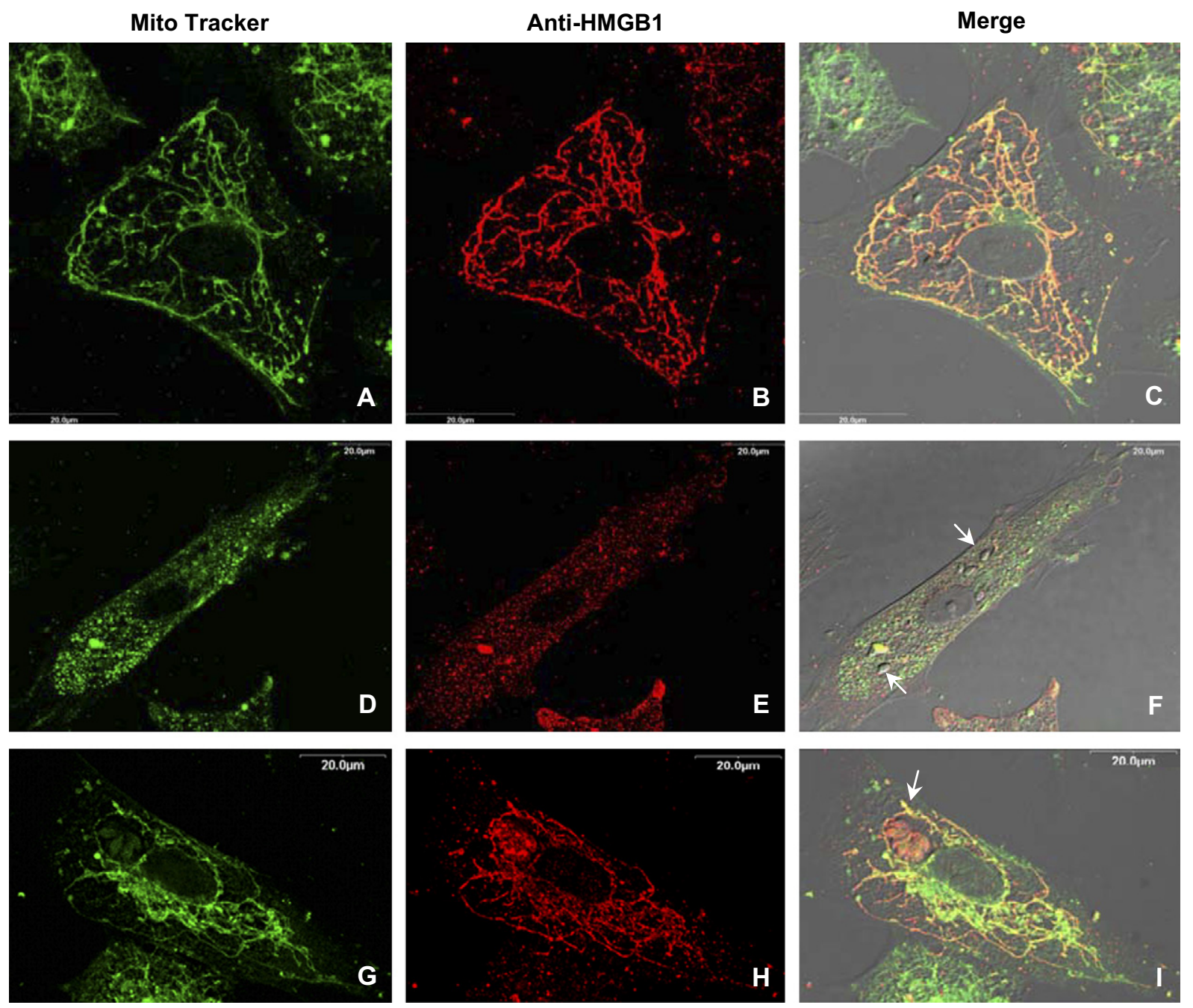

Fig. 1. Confocal laser scanning microscopy of endothelial cells stained with Mito Tracker Green FM (A, D and G) and immunolabeled with anti-HMGB1 (B, E and $\mathrm{H})$. Merged images show co-localization of HMGB1 in mitochondria (C, F and I). In non-infected cells the labeling was observed in filamentous pattern (A-C) and after $2 \mathrm{~h}$ of $T$. gondii infection, a large number of cells presented granular labeling scattered throughout the cytoplasm (D-F). However, after $24 \mathrm{~h}$ of interaction, the filamentous pattern was again observed, also around the parasitophorous vacuoles (arrows) containing rosettes (G-I).

could be a consequence of endothelial cell invasion by $T$. gondii. In addition, HMGB1's typical function as a DNA binding protein could be occurring with mitochondrial DNA (mtDNA). Transcriptional regulation of genes within mitochondria is primarily mediated by mitochondrial transcription factor (Tfam), a protein factor that contains a HMG box DNA binding motif (Parisi and Clayton, 1991), so we suggest that HMGB1 within the mitochondria could act in concert with Tfam and play a part in mtDNA events which are important for mitochondrial fission and fusion processes reported here during HUVEC- $T$. gondii infection.

\section{Acknowledgments}

Supported by Fundação Carlos Chagas Filho de Amparo à Pesquisa do Estado do Rio de Janeiro (FAPERJ), Conselho Nacional de Desenvolvimento Científico e Tecnológico (CNPq) and Coordenação de Aperfeiçoamento de Pessoal de
Nível Superior (Capes). The text was thoroughly revised in English by Prof Paul Dykstra of London.

\section{References}

Bereiter-Hahn J, Voth M. Dynamics of mitochondria in living cells: shape changes, dislocations, fusion, and fission of mitochondria. Microsc Res Tech 1994;27:198-219.

Bossy-Wetzel E, Barsoum MJ, Godzik A, Schwarzenbacher R, Lipton SA. Mitochondrial fission in apoptosis, neurodegeneration and aging. Curr Opin Cell Biol 2003;15:706-16.

Bustin M. Regulation of DNA-dependent activities by the functional motifs of the high-mobility-group chromosomal proteins. Mol Cell Biol 1999; 19:5237-46.

Carruthers VB. Host cell invasion by the opportunistic pathogen Toxoplasma gondii. Acta Trop 2002;81:111-22.

Carruthers V, Boothroyd JC. Pulling together: an integrated model of Toxoplasma cell invasion. Curr Opin Microbiol 2007;10:83-9.

Carvalho L, de Souza W. Cytochemical localization of plasma membrane enzyme markers during interiorization of tachyzoites of Toxoplasma gondii by macrophages. J Protozool 1989;36:164-70. 
Chan DC. Mitochondrial fusion and fission in mammals. Annu Rev Cell Dev Biol 2006;22:79-99.

Chen H, Chan DC. Emerging functions of mammalian mitochondrial fusion and fission. Hum Mol Genet 2005;14(Spec No. 2):R283-9.

de Melo EJ, de Carvalho TU, de Souza W. Penetration of Toxoplasma gondii into host cells induces changes in the distribution of the mitochondria and the endoplasmic reticulum. Cell Struct Funct 1992; $17: 311-7$.

Dement GA, Treff NR, Magnuson NS, Franceschi V, Reeves R. Dynamic mitochondrial localization of nuclear transcription factor HMGA1. Exp Cell Res 2005;307:388-401.

Jaffe EA, Nachman RL, Becker CG, Minick CR. Culture of human endothelial cells derived from umbilical veins. Identification by morphologic and immunologic criteria. J Clin Invest 1973;52:2745-56.

Jendrach M, Pohl S, Voth M, Kowald A, Hammerstein P, Bereiter-Hahn J. Morpho-dynamic changes of mitochondria during ageing of human endothelial cells. Mech Ageing Dev 2005;126:813-21.

Martin AM, Liu T, Lynn BC, Sinai AP. The Toxoplasma gondii parasitophorous vacuole membrane: transactions across the border. J Eukaryot Microbiol 2007;54:25-8.

Morisaki JH, Heuser JE, Sibley LD. Invasion of Toxoplasma gondii occurs by active penetration of the host cell. J Cell Sci 1995;108(Pt 6): 2457-64.

Muller S, Scaffidi P, Degryse B, Bonaldi T, Ronfani L, Agresti A, et al. New EMBO members' review: the double life of HMGB1 chromatin protein: architectural factor and extracellular signal. Embo $\mathrm{J}$ 2001;20:4337-40.

Mullins GE, Sunden-Cullberg J, Johansson AS, Rouhiainen A, ErlandssonHarris H, Yang H, et al. Activation of human umbilical vein endothelial cells leads to relocation and release of high-mobility group box chromosomal protein 1. Scand J Immunol 2004;60:566-73.
Pacheco-Soares C, De Souza W. Redistribution of parasite and host cell membrane components during Toxoplasma gondii invasion. Cell Struct Funct 1998;23:159-68.

Parisi MA, Clayton DA. Similarity of human mitochondrial transcription factor 1 to high mobility group proteins. Science 1991;252:965-9.

Parone PA, Martinou JC. Mitochondrial fission and apoptosis: an ongoing trial. Biochim Biophys Acta 2006;1763:522-30.

Reeves R, Adair JE. Role of high mobility group (HMG) chromatin proteins in DNA repair. DNA Repair (Amst) 2005;4:926-38.

Seth RB, Sun L, Ea CK, Chen ZJ. Identification and characterization of MAVS, a mitochondrial antiviral signaling protein that activates NFkappaB and IRF 3. Cell 2005;122:669-82.

Sinai AP, Joiner KA. The Toxoplasma gondii protein ROP2 mediates host organelle association with the parasitophorous vacuole membrane. J Cell Biol 2001;154:95-108.

Sinai AP, Webster P, Joiner KA. Association of host cell endoplasmic reticulum and mitochondria with the Toxoplasma gondii parasitophorous vacuole membrane: a high affinity interaction. J Cell Sci 1997;110(Pt 17):2117-28.

Stumbo AC, Barbosa HS, Carvalho TM, Porto LC, Carvalho L. Anionic sites, fucose residues and class I human leukocyte antigen fate during interaction of Toxoplasma gondii with endothelial cells. Mem Inst Oswaldo Cruz 2002;97:517-22.

Vidal JE, Hernandez AV, de Oliveira AC, Dauar RF, Barbosa Jr SP, Focaccia R. Cerebral toxoplasmosis in HIV-positive patients in Brazil: clinical features and predictors of treatment response in the HAART era. AIDS Patient Care STDS 2005;19:626-34.

Wang X. The expanding role of mitochondria in apoptosis. Genes Dev 2001;15:2922-33.

Woodman JP, Dimier IH, Bout DT. Human endothelial cells are activated by IFN-gamma to inhibit Toxoplasma gondii replication. Inhibition is due to a different mechanism from that existing in mouse macrophages and human fibroblasts. J Immunol 1991;147:2019-23. 